\title{
Study Coordinating Center
}

National Cancer Institute

\section{Source}

National Cancer Institute. Study Coordinating Center. NCI Thesaurus. Code C80431.

A consortium, network, or professional org anization or group that manages four specific responsibilities in connection with a study (protocol): study protocol concerns, registration of subjects, statistics, and study data. 